TI 2011-142/3

Tinbergen Institute Discussion Paper

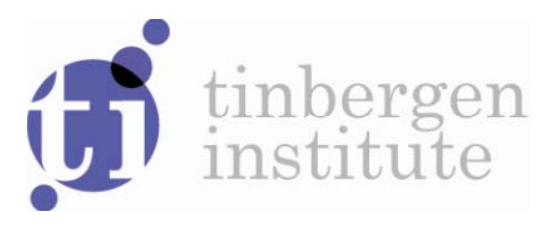

\title{
A Multi-Scenario Forecast of Urban Change: \\ A Study on Urban Growth in the Algarve
}

Eric de Noronha Vazl,2

Peter Nijkamp3

Marco Painho'

Mario Gaetano'

' Universidade Nova de Lisboa, Lisbon, Portugal;

2 Wirtschaftsuniversität Wien, Vienna, Austria;

3 VU University Amsterdam, and Tinbergen Institute. 
Tinbergen Institute is the graduate school and research institute in economics of Erasmus University Rotterdam, the University of Amsterdam and VU University Amsterdam.

More TI discussion papers can be downloaded at http://www.tinbergen.nl

Tinbergen Institute has two locations:

Tinbergen Institute Amsterdam

Gustav Mahlerplein 117

1082 MS Amsterdam

The Netherlands

Tel.: +31(0)205251600

Tinbergen Institute Rotterdam

Burg. Oudlaan 50

3062 PA Rotterdam

The Netherlands

Tel.: +31(0)10 4088900

Fax: $+31(0) 104089031$

Duisenberg school of finance is a collaboration of the Dutch financial sector and universities, with the ambition to support innovative research and offer top quality academic education in core areas of finance.

DSF research papers can be downloaded at: http://www.dsf.nl/

Duisenberg school of finance

Gustav Mahlerplein 117

1082 MS Amsterdam

The Netherlands

Tel.: +31(0)20 5258579 
A Multi-scenario for ecast of urban change: a study on urban growth in the Algarve

\author{
Eric de Noronha Vaz ${ }^{1,2}$; Peter Nijkamp ${ }^{3}$; Marco Painho ${ }^{1}$; Mário Caetano ${ }^{1}$
}

\begin{abstract}
The Algarve region in Portugal is often considered as one of the most appealing regions for tourism in the country. Its attractive location and moderate climate have since the mid-1960s brought increasing economic prosperity. As a result of the development of mass tourism, available land-use resources were widely exploited to create an integrated tourist industry. This region has shown an increasing loss of ecosystems resulting from the expansion of urban areas. This has also been accompanied by a significant abandonment of rural areas and hinterlands, leading to loss of agriculture and other rural activities. Clearly, urban growth needs considerable attention in the context of sustainable development, as often peri-urban areas with fragile ecosystems are becoming increasingly vulnerable. This paper aims to develop and apply key tools to quantify the changes of land use and how this affects the regional spatial scope by using multitemporal inventorying and accounting of land-use change matrices. Using Cellular Automata and a combined interpretation of CORINE Land Cover Data, it converges into a qualitative to quantitative interpretation of land use change by means of Multi-Criteria Evaluation. Finally, our analysis to identify the scenario with the best fit, based on the evolution of the actual 2006 land cover, enabled us to build a future urban growth model for 2020 which was quantitatively assessed. The outcome suggests a picture of continuing growth for the region of the Algarve within the framework of current policies and regressive spatial trends.
\end{abstract}

Keywords: Urban growth; Algarve; CORINE Land Cover; Scenario modelling

\footnotetext{
${ }^{1}$ Universidade Nova de Lisboa - Higher Institute of Statistics and Information Management, Lisbon, Portugal

${ }^{2}$ Wirtschaftsuniversität Wien - Institut für Wirtschaftsgeographie und Geoinformatik, Vienna, Austria

${ }^{3}$ VU University - Department of Spatial Economics, Amsterdam, The Netherlands
} 


\section{Introduction}

Europe has experienced unprecedented urban change and population increase over the last 30 years and this is expected to continue (Cohen, 2004). In 2008, the population of the European Union (EU) rose by 2.1 million, resulting in the growth of GDP by 0.4 per cent. Europe's multi-cultural and liberal policies have directly contributed to the expansion of the EU, making it today the strongest world economy (Moravcsik, 1993). However, the downside of this population increase is reflected in the rapid land-use cover change (Bilsborrow and Ogendo, 1992), especially within the metropolitan areas of larger cities in the EU, or other important socio-economic areas (EEA, 2006a).

The European Cohesion Policy (2007-2013) recognizes the complexity of urban sprawl, and proposes a coordinated and integrated approach for sustainable development in urban and rural areas (CEC, 2006). This policy focuses mainly on ameliorating specific impacts of urban sprawl by recommending actions for coordination of land use policies. The actions that are chiefly taken into account are related to: challenging the distribution of the structural cohesion funds and investments between urban and rural areas; delegating of funds within structural fund operational programmes; regulations of EU laws on air quality, waste-water treatment, waste management, water supply and environmental noise; and co-financing activities under the structural funds based on plans that address environmental quality of urban areas in coastal regions (EEA, 2006b).

In the case of Portugal, these issues are reinforced at the regional level by the existing municipal plans, and within the framework of the National Policy and Territorial Management Programme (Programa Nacional da Política de Ordenamento do Território - PNPOT). The PNPOT explains the ongoing urban sprawl in the Portuguese region as being chiefly due to the construction of new residences within less densely populated areas, contributing directly to the growth of private transportation and the increase of urban sprawl in peripheral urban areas, and creating uneven urban growth (PNPOT, 2007). At the regional level, the PROT (Plano Regional de Ordenamento de Território Regional Plan for Territorial Planning) supports the development of NUTS-III areas in 
Portugal within the common framework of the PNPOT, including specific efforts on sustainable development and environmental quality.

Urban growth models have proved to be important tools to measure land-use change in peri-urban and rural regions (Tobler, 1970; White et al., 1997; Clarke and Gaydos, 1998; Herold et al., 2003; Mundia and Murayama, 2010) in strong connection with decision support systems. The technological development of remote sensing imagery with higher accuracy has led to the creation of high-resolution spatial imagery which makes it possible to extract more accurate topological and geomorphological characteristics (White and Engelen, 2000; Sawaya et al., 2003; Picón-Feliciano, 2009), which are fundamental for spatial modelling experiments. Furthermore, in recent years elaborate algorithms have been constructed that manage to filter relevant human information in a context of land-use dynamics. Examples of the extraction of such information are: industrial areas, urban areas and other artificial terrains which have an impact on landuse, such as golf courses in the Algarve region. The aggregation of spatial coverage, whether geological or socio-economic, allows complex system dynamics and subsequent spatial land-use analysis. This application of spatial models to achieve a balance between the environment and the management of scarce resources (Goudie, 2006) supports the adequate decision-making strategies.

One of the key elements within the context of socio-economic land-use change is that within the inherent complexity of environmental change, man-induced change is fundamentally self-organized (Moussaïd et al., 2009). From a classical perspective, the multiplication of households triggers location-specific amenities which directly or indirectly shape urban regions, as pointed out by Straszheim (1987). Possible triggers for urban growth may be identified by the measurement of externalities which exert an impact on land-use change. As long as externalities are spatially explicit, the socioeconomic dimension of land-use becomes a ubiquitous phenomenon which may be analyzed and distinguished at a spatial level. 


\section{The Algarve Region}

The most southern part of Portugal is the Algarve. With a very heterogeneous geography (Drain, 1989), the region has a cultural legacy that goes back to pre-Roman civilizations (Gamito, 1997). Over the last few years, the Portuguese tourist sector has increased to a 9.2 per cent share of GDP. As pointed out by Correia and Crouch (2004), the Algarve is Portugal's prime destination for tourism, mainly due to its beaches and climate, and accounts for $42 \%$ per cent of Portugal's tourist activity.

The rapid increase of the tourism sector in the mid-1960s led to urban growth and the creation of supporting infrastructures, generating high revenues and economic growth for the region and resulting in the modernization and generation of infrastructures. Buhalis and Fletcher (1995) question the symbiotic and antagonistic factors that should be considered regarding sustainable development in tourism. One of the reasons for this is that, before the 1990s, the distinction between growth and development was quite unclear. Growth was envisioned as a unique driver for economic prosperity. Economic growth however, is far from being sustainable and one of the main consequences of this economic anthropocentric growth perspective has been the depletion of available resources. This has led to constant pressure on the environment and resulted in environmental changes that may be measured in terms of several dimensions of which the human impact represents the main driver, resulting from factors related to acceleration of the information society, population and urban growth, the human impact on the carrying capacity of the environment, and the globalization of environmental deficiencies. (Camhis, 2006).

In the case of the Algarve, the land-use change has been drastic, and the consequences for the coastal areas of the region have had a direct impact on fragile existing ecosystems such as the Ria Formosa. The Ria Formosa is a shallow lagoon, designated as a Natural Park because of its important ecological value, given the diversity of indigenous species which exist in the region. This area supports many different services which benefit the regional economy, such as aquaculture, salt production and tourism. The degradation of this lagoon, as analysed by Nobre (2009), is a serious sign of the environmental 
degradation of the region, and of the antagonistic impacts of human behavior on ecosystems.

The symbiotic effect of ecosystems in coastal zones is especially relevant because of the high economic value generated by leisure services available within those areas (Costanza et al., 1997). According to Boissonnas and others (2002), 43\% of the ecosystem services are provided by coastal environments. However, population increase and related socioeconomic aspects generate pressures within those habitats (Meyer and Turner, 1992), putting those coastal ecosystems at permanent risk. Monitoring the anthroposphere (that is, the combination of artificial land use, population change, and peri-urban growth) provides important information to preserve and manage such habitats. Urban pressure in the region has been shown to be an important factor for the increasing pressures on the shores of the wetlands and its surroundings. Human impact seems to be the main driver for the loss of biodiversity, leading to euthrophication of the fragile ecological habitat of the Ria Formosa (Newton et al., 2003).

\section{Land-use Maps and Urban Dynamics}

The CORINE Land Cover (CLC) project started in 1985, and addressed the following issues at the spatial level: State of individual environments; Geographical distribution and state of natural areas; Geographical distribution and abundance of wild fauna and flora; Quality and abundance of water resources; Land-cover structure and the state of the soil; Quantities of toxic substances discharged into the environment; and a list of Natural Hazards (EEA, 1995). According to a European Union decision, the CLC may be seen as (85/338/EEC, Council Decision 27/6/1985) an experimental project for gathering, coordinating and ensuring the consistency of information on the state of the environment and natural resources in the Community.

Because of its multi-temporal land-use inventories, the CLC project may be considered a very suitable methodology to trace and better understand land-use change (Paínho and Caetano, 2006). The combination of socio-economic data and thematic information aids in the interpretation and analysis of land change. Valuable information can be extracted when change is analysed over time. 
Land-use maps have become witnesses of the indisputable loss of natural habitats, as a result of artificial land uses to enable the construction of infrastructures which relate to the tourist demand. When comparing urban areas in CLC 1990 and 2006, it can be seen that the class of urban land use has become double the size from CLC 1990. This growth is especially noticeable in the surroundings of the major cities of the Algarve, such as Portimão, Albufeira and Faro. In contrast, the interior of the Algarve has registered insignificant growth, while presenting higher levels of rural abandonment and loss of agriculture. A constant decrease from 44.55 per cent of agricultural land-use in CLC 1990 to 41.10 per cent in CLC 2000 and reaching to 40.06 per cent in CLC 2006 has been registered. The agricultural land loss has been accompanied by an increase in forest areas, which are the prevailing land use on areas of agricultural loss as an indication of rural and agricultural abandonment. Forest has increased from 50.22 per cent to 52.33 per cent in CLC 2006. These changes were mostly felt in rural areas, while peri-urban regions have become more urbanized

The CLC nomenclature has a total of three levels with a total of 64 items per level. The first level, includes the major categories: Artificial surfaces (urban); Agricultural areas; Forests and semi-natural areas; Wetlands and Water bodies. Figure 1 shows the change which has occurred over the period 1986-2000 of the CLC project. In comparison wetlands and water bodies remained somewhat constant with some increase of water bodies - this increase is a result of the loss of coastal area and tidal variations during the survey. Urban surfaces, Agricultural areas and Forest registered the most significant changes. The significant increase of artificial areas as mentioned earlier is mainly related to urban growth around city perimeters and is located mostly in the coastal zones. Urban growth showed the most dramatic changes over the period 1990 to 2006. The initial 1.94 per cent of urban areas from the CORINE Land Cover (CLC) 1990 period (1986-1990), doubles to 3.95 per cent in CLC 2006. This urban sprawl is observed mainly in the periurban regions of the Algarve, especially in the vicinity of coastal tourist areas where services are more abundant (Portimão, Albufeira and Faro). 


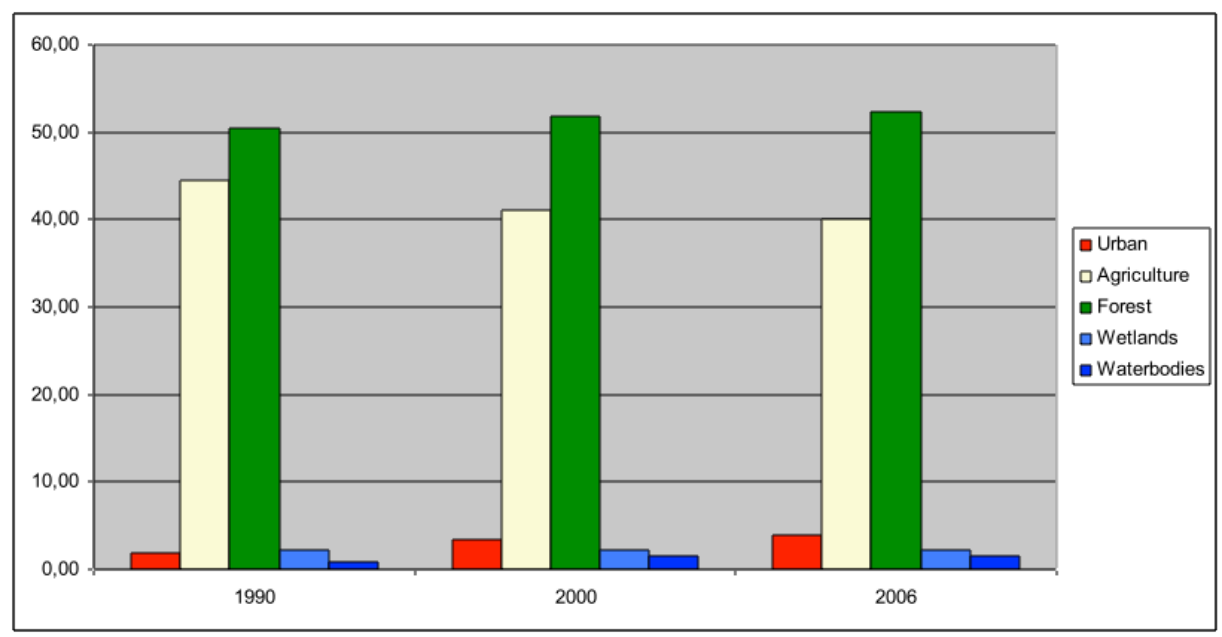

Figure 1 - CORINE Land Cover Classes in CLC 1990. CLC 2000 and CLC 2006

A closer analysis of the urban fabric in the region enabled us to assess the types of artificial land use that were constructed within the study period. During this period there was a marked tendency for building infrastructures. Previously unregistered road and rail networks were built (a variation of 1.55 per cent within study periods) as well as sports and leisure facilities (1.181\%, increase primarily due to the Euro 2004 football championship). These infrastructures are closely linked to Euro 2004, which stimulated a total investment of 30,351,354 $€$ in the region. However, as pointed out by Perna and Custódio (2007): “(...) the expectations generated in terms of economic impact on the accommodation industry have not been met. The cause-and-effect relationship between an optimistic forecast of strong growth in demand as desired by the industry agents and its non-fulfillment lead us to conclude that despite the minimized losses in economic terms, Algarve has not been able to capture and take advantage of the range of possible short-term gains associated with the event”. The generation of infrastructures to support Euro 2004 has been felt at a spatial level, and these construction sites have contributed to the ongoing loss of possible agricultural arable land.

\section{Multi-scenario Modelling of the Algarve}

Our approach is based on recent advances in geo-science modelling. Natural and socioeconomic variables may be seen as spatio-temporal drivers especially when related to 
urban systems (Han et al., 2009). Sensitivity maps based on variables of urban change have a scale of propensity for the existence of built-up environments, and are relevant tools to assess the dynamics of land-use change over a given period. As indicated in a foresight analysis by Pontius and Schneider (2001), the drivers are a subset of factors and constraints, calculated for the area of study and which when combined enable the visualization of urban change in time. However, the combination of variables to measure change dynamics is dependent on the drivers at the regional level, which justifies the importance of multi-criteria approaches to the stochastic analysis of urban change scenarios. Our calculation of a Multi-criteria Evaluation (MCE) suitability index relies on the physical, socio-economic, and regional characteristics, which are prioritized by means of an Analytical Hierarchy Process (AHP) (see Saaty, 1990) which led to the design of three scenarios with different pairwise quantification. The main advantage of AHP is related to the structural conceptualization of decision making, in which several values in a range of different scales may be compared. This comparison generates quantifiable priorities attached to different variables. It is therefore, a qualitative structural decision process that, rather than quantifying just one best decision, aggregates a range of different values balanced for decision making in a proper space-time context.

Next, a Markov transition matrix from the land-use inventories in our information system allows the spatial assessment of the proposed scenarios. One of the main advantages of this methodology is the capability to combine qualitative assessments from multiscenarios with quantifiable spatial analyses. This permits us to calculate a propensity for urban growth embedded within a Multi-criteria Evaluation (MCE) framework on the basis of forecasting economic, social and physical variables. Figure 2 below summarizes the methodological approach of the AHP / Multi-scenario / Markov transition process to represent the spatial dynamics of land-use by designing models which can predict the propensity for urban development.

The three distinct scenarios may be conceptualized as follows:

(i) Ecological Interest:

- Responsible planning and self-sufficiency through the development of agricultural activities in the interior area the Algarve; 
- Greater development of rural sectors of economic activity for traditional production and with specialized market strategies;

- Road networks are of some importance, but public transport should play a central role.

- Coastal proximity is less significant, and should be avoided whenever possible, so as not to overburden the already endangered coastal regions.

(ii) Business as Usual:

- Continuing development of the tourist industry along the coastal region of the Algarve, taking advantage of reduced costs in further urban growth in peri-urban areas while benefiting from good road networks;

- Increasing population density plays a significant role in the main cities of the regions such as Faro, Portimão, Loulé and Albufeira;

(iii) Economic Interest:

- Maximization of traditional economic growth through the creation of more infrastructures to support the mass-tourism industry;

- Continuing urban growth in urban perimeters, especially within areas with a high population density while generating more revenues in order to allow the service sectors to prosper;

As projected in Figure 2, the elements of the story-lines of each scenario of urban growth may be defined through the AHP process as different circles, in which the size of each circle (agriculture, urban proximity, road networks, coastal proximity and population density) represents the weighting used for each scenario (i, ii, iii). The size of those circles is compared within each of the scenarios, and this forms the basis of the table of the relative weights of the qualitative criteria, located in the bottom right-hand corner of Figure 2. The propensity for urban growth is calculated by means of the weights assigned to each value in each scenario. Eventually, this results later in the possibility to discern a Markov transition rule for the geography of urban sprawl. This framework model will for multiple scenario foresight analysis will now be applied to the Algarve region. 


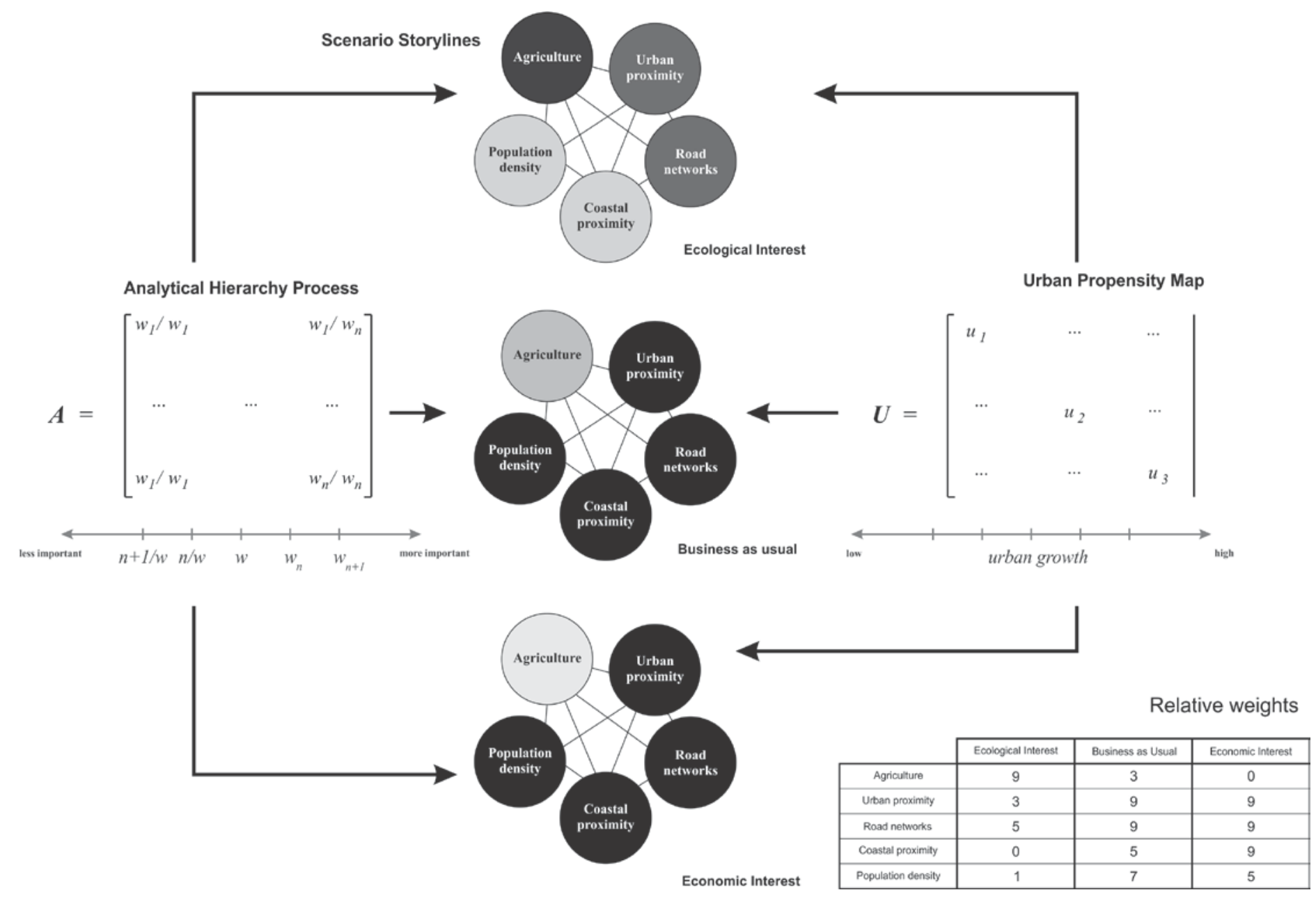

Figure 2 - Methodological conceptualization of integrated Multi-scenario Modelling approach 


\section{Projecting and Comparing Urban Growth in the Algarve - from 2006 to 2020}

The combination of the different subset of drivers enabled us to produce a series of maps showing the future urban growth sensitivity for the Algarve. The proportion of each colour (red and yellow and green) was controlled by a saturation of values ranging from 0-255. So, if maximum propensity should be found, saturated colour is maximized in red (255), while yellow and green are discarded. Middle ranged values of the distribution show a higher saturation of green, while low range saturation, that is, lowest propensity for urban development are saturated in the spectre of green. The resulting propensity for highest occurrence was established by creating a relative percentage of the 0-255 scale. The regions with highest values for urban growth (that is, with more saturation in red) were found in the Economic Interest and Business as Usual scenarios (Figure 3a, b). This corresponds to the propensity resulting from the integration of the Analytical Hierarchy Process (AHP) with the weights for each story-line.

The more rural oriented scenario (Figure 3a) shows no increase of urban areas on the fringe of the coastal regions. Also, for this particular scenario, the propensity score indicates a maximum likelihood of 54 out of 255 of transforming into urban, less than one fifth of the maximum registered in the Economic Interest scenario. A calculation of those sites was assessed on the resulting AHP combined with a probability indicator of higher propensity than 50 per cent. As expected, the Ecological Interest scenario output did not register any municipalities with a high propensity for further urban development. This may be interpreted as the shift to a more ecobalanced activity allowing using existing resources to be used, without overburdening the carrying capacity. Also, as areas become used for agricultural activity, the intensity of pressure on the carrying capacity of the coastal regions becomes less. While the Economic Interest scenario shows a higher growth in similar parishes as in the Business as Usual scenario, more urban sprawl is registered. Finally, the Business as usual scenario shows the most extension of construction. These extensions of construction are the result of urban sprawl, rather than urban growth, resulting from mixed policies that do not have a significant focus on decisional objectives and a lack of the use of agglomeration economies. These comparative results suggest that the Business as Usual scenario is the least efficient, in terms of both ecological impacts and 
socio-economic effects. On the one hand, the agglomeration of cities shows that the city, as a locus where cumulative learning may exist, allows knowledge spillovers and learning spaces (Capello and Nijkamp, 2004) which may be less endangering to the realisation of a sustainable environment.
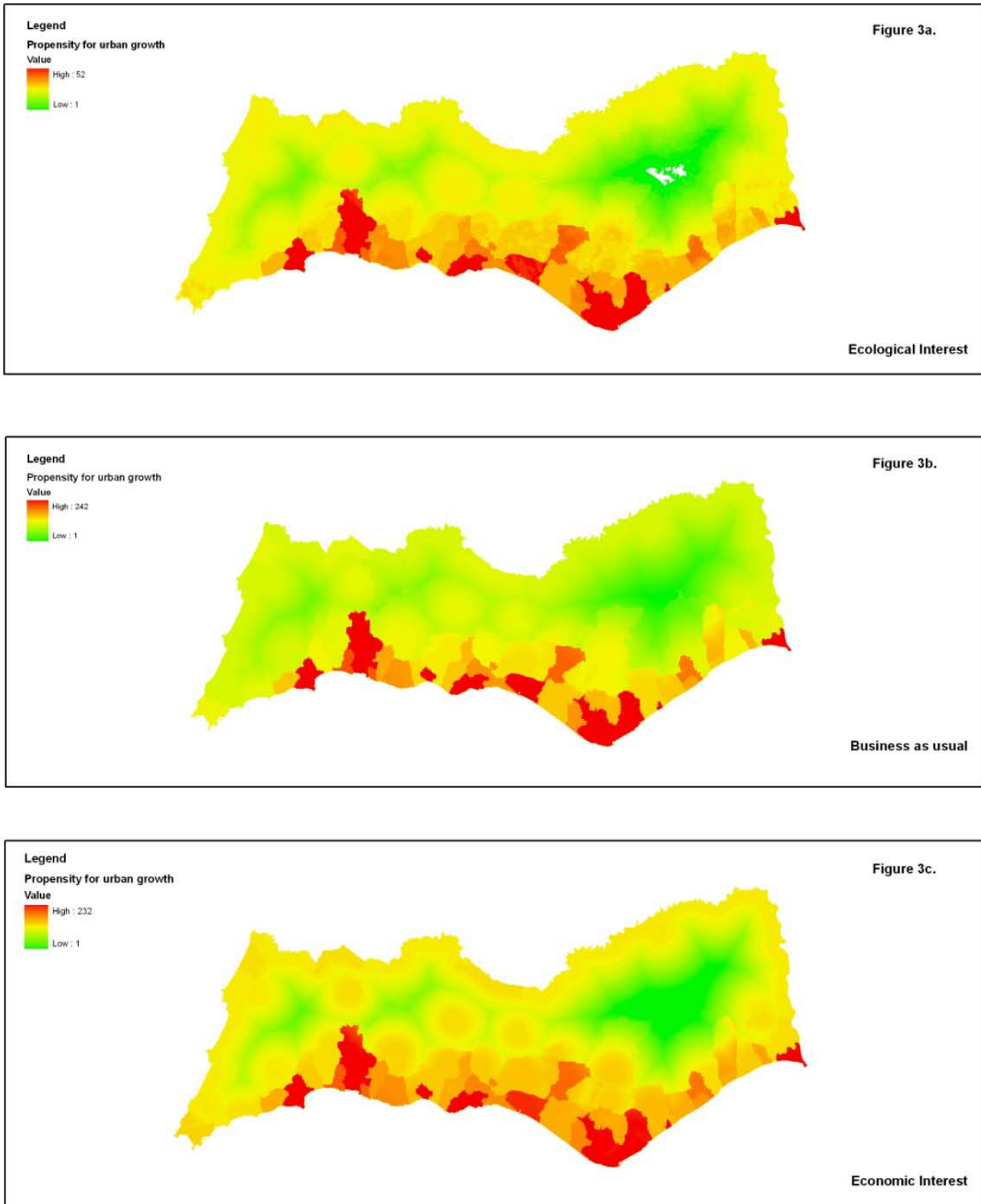

Figure 3 - Comparative urban sensitivity of multi-scenarios 
On the other hand, the Ecological Interest scenario demonstrates the possibility of stimulating agricultural efficiency which would limit urban growth, as rural activities do not rely on the construction of so many infrastructures. However, this model is less probable, as it calls for a much too radical shift of the economy-centred growth paradigm which combines physical proximity to population dynamics with economic prosperity. Most constraining for the environment are the residues of urban sprawl which are current trends within the region, as they affect much more volatile territory than either of the other scenarios.

\section{Cellular Automata for Urban Growth For ecasting}

Based on the CORINE Land Cover (CLC) and the information on its main classes, a transition matrix was compiled, using Markov transition probabilities. Such a matrix indicates the likelihood of changes from one state to another. This is very suitable for land-use change analysis, especially when combined with cellular automata iteration rules, which allow the transition probabilities to become spatially explicit (Barredo et al. 2003). The conditional probabilities of changing from one state to another are then assembled within a given set of socio-economic constraints. The following transition probabilities were obtained (Table 1).

Table 1 - Transition Matrix of Markov Chains from CLC00 based on CLC90

\begin{tabular}{|l|l|c|c|c|c|c|}
\hline & & \multicolumn{5}{|c|}{ Probability of changing to: } \\
\hline \multirow{4}{*}{ Land class } & & Urban & Agriculture & Forest & Wetlands & Waterbodies \\
\cline { 2 - 7 } & Frban & 0.83 & 0.06 & 0.07 & 0.03 & 0.01 \\
\cline { 2 - 7 } & Agriculture & 0.07 & 0.77 & 0.15 & 0.00 & 0.01 \\
\cline { 2 - 7 } & Wetlands & 0.04 & 0.11 & 0.83 & 0.00 & 0.01 \\
\cline { 2 - 7 } & Waterbodies & 0.03 & 0.01 & 0.10 & 0.84 & 0.02 \\
\hline
\end{tabular}


A couple of interesting points are apparent from the stochastic comparison of probability transition: (i) the class of most occurring change is expected to be the transition from agricultural to urban land use; (ii) forest areas register the highest probability of changing into agricultural land; and finally (iii) a relationship exists between the possible evolution of wetlands to areas anticipated to be coniferous forests.

The previous relations reveal the ecological transitions of the ecosystem of the Algarve quite well: Agricultural abandonment is leading to an increase of forest areas, while these areas are then more likely to be used for urban growth, due to their physical and geographical characteristics. The wetlands in the Algarve are mostly found in the coastal perimeters, which are known to be areas of enormous environmental pressure. We experimented with a number of methodological refinements: the figure below represents the approach for validating and projecting land-use change within the multi-scenario approach (Figure 4). 


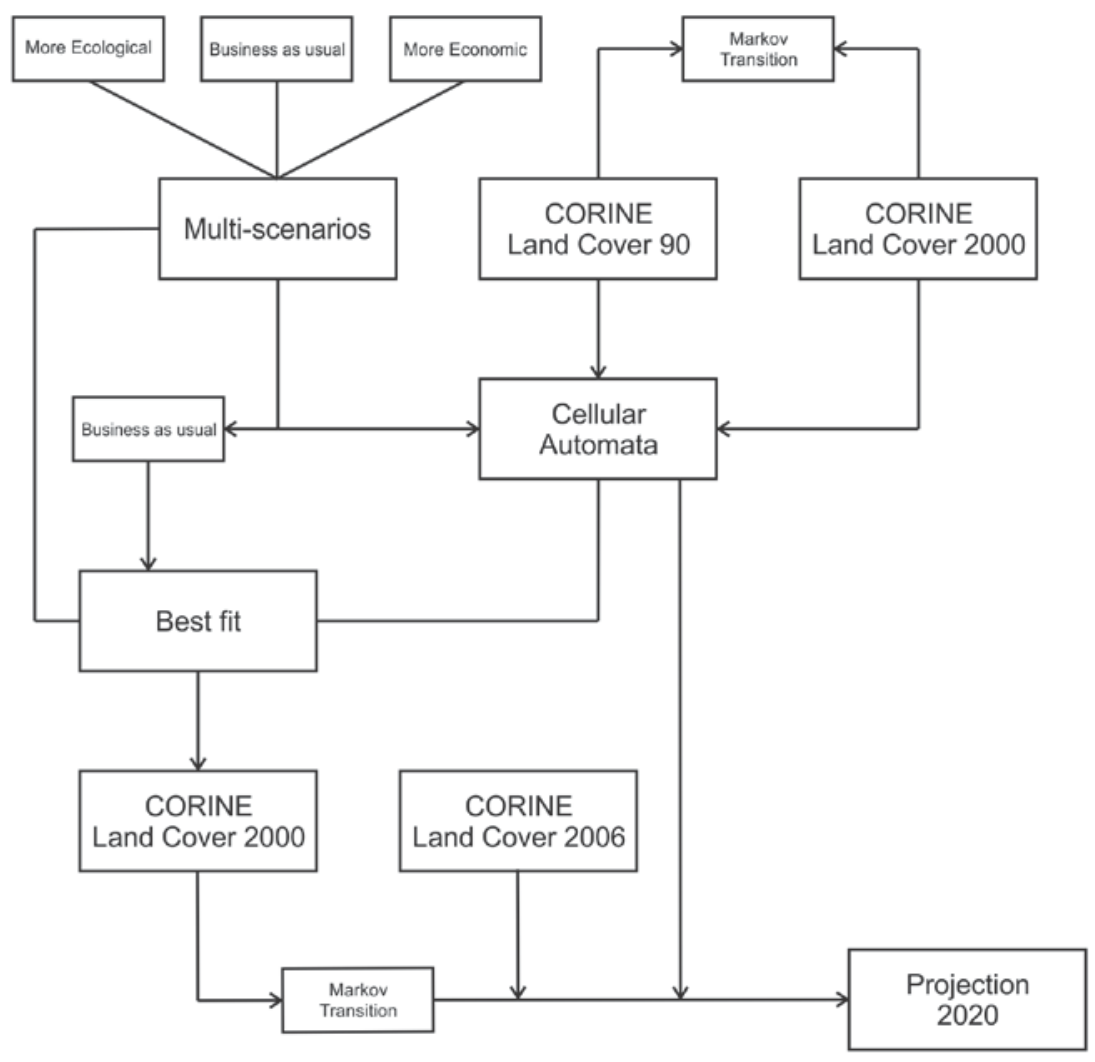

Figure 4 - Diagram of validation and projection

The first steps involved connecting the different scenarios with the base land covers from CLC 1990 and CLC 2000. The calculated values of Markov transition chains from the five different classes (Urban areas, Agriculture, Forest, Wetlands and Water bodies) were assessed by means of a Cellular Automata algorithm which represents the spatial properties of the Markov transition matrices.

The three generated outcomes are compared with the base data set of CORINE Land Cover 2006 via the generation of a statistical Kappa, showing the margin of error for each of the calculated scenarios. As may be seen, the Business as Usual scenario is the most likely scenario as it shows the clearest similarity to the CORINE Land Cover 2006. Two conclusions can be drawn from this comparison: Our Cellular Automata approach allowed a stable analysis of the real 
transformation of land use, suggesting that Markov propensities related to Cellular Automata approaches have interesting capabilities for land use change analysis. Furthermore, the comparison of the results from land changes in the other scenarios, lead to important results on the differentiation of strategies for policymakers regarding the choice of different strategies.

The most deviant results were found in the Ecological Interest model, which did not envision the trend of urban growth which has occurred up to 2006. The best-fit analysis involves the comparison of each class of each calculated scenario in its amplitude of change value related to the CLC 2006 projection:

where is the best fit of the amplitude of propensity for urban change most similar to the original land-cover class; and corresponds to the scenario and each representing class and the quantified results per class on the land cover, whose value for best fit equals the value closest to zero. The following results were obtained:

Table 2 - Results from the best-fit analysis

\begin{tabular}{|l|r|r|r|}
\hline & \multicolumn{2}{|c|}{ Scenario } \\
\hline & Ecological & Economical & \multicolumn{1}{|c|}{ Business as } \\
usual \\
\hline Urban areas & 0.94 & 5.12 & 3.88 \\
\hline Agricultural areas & 7.68 & 2.98 & 1.81 \\
\hline Forests & 8.29 & 7.63 & 2.06 \\
\hline Wetlands & 0.16 & 0.18 & 0.01 \\
\hline Water bodies & 0.49 & 0.65 & 7.76 \\
\hline best-fit & 17.56 & 16.56 & \\
\hline
\end{tabular}


As the best-fit was found in the 'Business as Usual' scenario, the projection of land-use change for 2020 is done in a similar manner through iterating values based on our CLC 2006 land cover, with CLC 1990 and CLC 2000 as reference.

\section{7- Conclusions}

The iterations of the cellular automata related to similar Markov transition rules, enabled us to generate the future urban growth scenario for the year 2020 (Figure 5). While urban growth seems to be increasing along all the coastal regions of the Algarve, the region between Albufeira, Portimão and Faro, Olhão is of most concern. Similarly, former agricultural land is being converted into urban areas around Portimão.

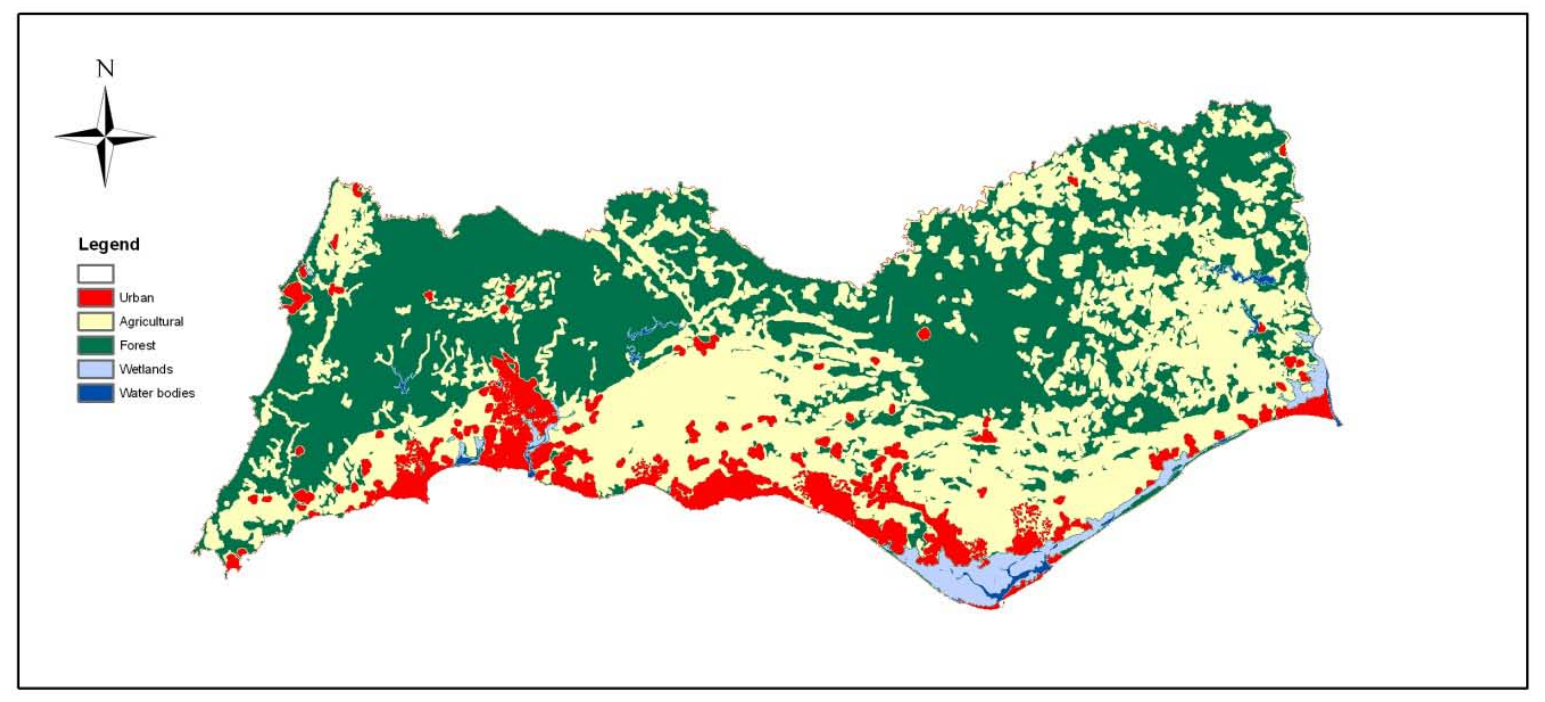

Figure 5 - Urban growth projection for 2020

The overall assessment of land-use change in the coming years, given the current strategies for development, will lead to growing cities which remain very close to the coastal areas. The analysis of the central region of the Algarve between Faro and Portimão shows that the existing road networks play an important role in urban growth. Also, an agglomeration of artificial land 
use is visible in the coming years, especially in and around the district capital of Faro and in the vicinity of different parishes which during the 1990s did not report significant urban growth tendencies. Another concern is noticeable in the form of rural abandonment, witnessed by an unprecedented increase of coniferous forest areas, and accompanied by loss of agricultural sectors. The divergence between the urban scene and rural regions is becoming more accentuated over time, showing lack of integration of policies designed to achieve sustainable development in the coming years.

The results for the Algarve suggest that the region should focus on the diversification of sectors of economic activity, offering new solutions for the regions, other than tourism. Although tourism is an important economic activity for the Algarve and Portugal as a whole, it is of utmost importance to use the creation of infrastructures wisely, especially regarding their distribution, so as not to overburden the carrying capacity of the natural environment, caused mainly by urban sprawl and rural abandonment.

This paper has proposed a new methodology, which combines different tools for the spatial analysis of future urban land-use scenarios. The use of Cellular Automata within qualitative modelling approaches produced novel results for scenario modelling of alternatives for future urban design trends. The handling of such scenario-modelling approaches may involve a broad range of land-use analysis and strongly suggests future areas of study. The novelty of this methodology is that it produces very interesting results regarding the gap between qualitative analysis and quantitative outputs, especially when related to spatial decision-making support systems, in which combined methodologies may have a leading role in better decision-making.

\section{References}

Barredo, J. I., Kasanko, M., McCormick, N., Lavalle, C. (2003), Modelling dynamic spatial processes: simulation of urban future scenarios through cellular automata, Landscape and Urban Planning, 64(3): 145-160. 
Bilsborrow, R. E. and Ogendo, H. W. O. O. (1992), Population-driven changes in land use in developing countries. Ambio, 21(1): 37-45.

Boissonnas, J., Connolly, N., Mantoura, F., D’Ozouville, L., 2002. Integrating Marine Science in Europe. European Science Foundation Marine Board, 148 pp.

Buhalis, D. and Fletcher J. (1995), Environmental impacts on tourist destination: an economic analysis. In P. Nijkamp and H. Coccossis (eds.), Sustainable Tourism Development, Avebury: Ashgate, pp. 3-24.

Camhis, M. (2006), Sustainable Development and Urbanization In:M. Keiner (ed.) The Future of Sustainability, Dordrecht: Springer, pp. 69-99.

Capello R. and Nijkamp, P. (2004), The Theoretical and Methodological Toolbox of Urban Economics: From and Towards Where?, In R. Capello and P. Nijkamp (eds.), Urban Dynamics and Growth: Advances in Urban Economics, Elsevier: Amsterdam, pp. 1-30

CEC (Commission of the European Communities) (2006), Cohesion Policy and cities: the urban contribution to growth and jobs in the regions, Brussels: European Commission.

Clarke, K. and Gaydos, L. 1998. Loose-coupling a cellular automaton model and GIS: long-term urban growth prediction for San Francisco and Washington/Baltimore. International Journal of Remote Sensing, 12(7): 699-714.

Cohen, B. (2004), Urban growth in developing countries: A review of current trends and a caution regarding existing forecasts. World Development, 32(1): 23-51. 
Correia, A. and Crouch, G. I. (2004). A Study of Tourist Decision Processes: Algarve, Portugal, (In: G. I. Crouch, R. R. Perdue, H. J. P. Timmermans and M. Uysal (eds.), Consumer Psychology of Tourism, Hospitality and Leisure, Oxfordshire, UK: Cabi Publishing.

Costanza, R., D’Arge, R., de Groot, R., Farber, S., Grasso, M., Hannon, B., Limburg, K., Naeem, S., O’Neill, R. V., Paruelo, J., Raskin, R. G., Sutton, P. and Belt, M. van den (1997), The value of the world's ecosystem services and natural capital. Nature, 387: 253-260.

Drain, M. (1989), L’Algarve et la notion Geographique d’Arriere-Pays. In: M. Gomes Guerreiro (ed.), O Algarve - Na perspectiva da Antropologia Ecológica. Lisboa: INIC, pp. 61-72.

EEA (1995), CORINE Land Cover, EEA Report (consulted on 05.08.09, http://www.eea.europa.eu/publications/COR0-landcover).

EEA (2006a), Urban sprawl in Europe - The ignored challenge, EEA Report No 10/2006 (consulted on 18.02.10, www.eea.europa.eu/publications/eea_report_2006_10).

EEA (2006b), The changing faces of Europe's coastal areas, EEA Report No 6/2006 (consulted on 05.08.09, http://www.eea.europa.eu/publications/eea_report_2006_6).

GAMITO, T. J. (1997), A cidade de Ossonoba e o seu território envolvente In Noventa séculos entre a serra e o mar, Lisbon: IPPAR, pp. 343-360.

Goudie, A. (2006), The human impact on the natural environment: Past, present, and future. UK: Blackwell Publishers.

Han, J., Hayashi, Y. and Cao, X. (2009), Application of an integrated system dynamics and cellular automata model for urban growth assessment: A case study of Shanghai, China, Landscape and Urban Planning, 91(3): 133-141. 
Herold, M., Goldstein, N. and Clarke, K. 2003. The spatio-temporal form of urban growth: measurement, analysis and modeling. Remote Sensing of Environment, 85: 95-105.

Longley, P. (2002) “Geographical Information Systems: will developments in urban remote sensing and GIS lead to ‘better’ urban geography?’ Progress in Human Geography, pp. 26 - 31.

Meyer, W. B. and Turner, B. L. (1992), Human population growth and global land-use/cover change. Annual Review of Ecology and Systematics, 23(1): 39-61.

Moravcsik, A. (1993). Preferences and power in the european community: A liberal intergovernmentalist approach. Journal of Common Market Studies, 31: 473-473.

Moussaïd, M., Helbing, D., Garnier, S., Johansson, A., Combe, M., and Theraulaz, G. (2009), Experimental study of the behavioural mechanisms underlying self-organization in human crowds. Proceedings. Biological Sciences / the Royal Society, 276(1668): 2755-2762.

Mundia, C. N. \& Murayama, Y. (2010), Modeling spatial processes of urban growth in african cities: A case study of Nairobi city. Urban Geography, 31(2): 259-272.

Newton, A., Icely, J. D., Falcao, M., Nobre, A., Nunes, J. P., Ferreira, J. G. and Vale, C. (2003), Evaluation of eutrophication in the Ria Formosa coastal lagoon, Portugal. Continental Shelf Research, 23: 1945-1961.

Nobre, A. (2009), An Ecological and Economic Assessment Methodology for Coastal Ecosystem Management, Environmental Management, 44:185-204.

Paínho, M. and Caetano, M. (2006), Cartografia de Ocupação do Solo: Portugal Continental, 1985-2000: CORINE Land Cover 2000, Amadora: Instituto do Ambiente. 
Perna, F. and Custódio, M. J. (2007), The Importance of Events in Tourism: The case of UEFA EURO 2004 on the Tourism Economy in the Algarve, Anatolia: An International Journal of Tourism and Hospitality Research, 19 (1): 5-22.

Picón-Feliciano, A. J., Vásquez, R., González, J., Luvall, J., and Rickman, D. (2009), Use of remote sensing observations to study the urban climate on tropical coastal cities. Revista Umbral, (1): 218-232.

Pontius, R.G. and Schneider, L.C. (2001), Land-cover change model validation by a ROC method. Agriculture, Ecosystems \& Environment. 85: 239-248.

PNPOT (2007) (Programa Nacional da Política de Ordenamento do Território), Relatório, consulted at: http://www.territorioportugal.pt/pnpot/

Saaty, T. L., (1990), How to make a decision: The analytic herarchy process, European Journal of Operational Research. 48(1): 9-26.

Sawaya, K. E., Olmanson, L. G., Heinert, N. J., Brezonik, P. L. and Bauer, M. E. (2003), Extending satellite remote sensing to local scales: land and water resource monitoring using high-resolution imagery. Remote Sensing of Environment, 88: 144-156.

Straszheim, M. (1987), The theory of urban residential location. In: P. Nijkamo (ed.), Handbook of Regional Economics. North-Holland Publ. Co.: Amsterdam, pp. 717-757.

Tobler, W. R. (1970), A Computer Movie Simulating Urban Growth in the Detroit Region, Economic Geography, 46: 234-240. 
White, R. and Engelen, G. (2000), High-resolution integrated modelling of the spatial dynamics of urban and regional systems. Computers, environment and urban systems, 24: 383-400.

White, R., Engelen, G. and Uljee, I. (1997), The use of constrained cellular automata for highresolution modelling of urban land use dynamics. Environment and Planning B, 24: 323-343 